\title{
Supraspinal Control of Urine Storage and Micturition in Men-An fMRI Study
}

\author{
Lars Michels ${ }^{1}$, Bertil F.M. Blok ${ }^{2}$, Flavia Gregorini ${ }^{3}$, Michael Kurz ${ }^{4}$, Brigitte Schurch ${ }^{5}$, Thomas M. Kessler ${ }^{3}$, Spyros Kollias ${ }^{1, \dagger}$ \\ and Ulrich Mehnert ${ }^{3, \dagger}$

\begin{abstract}
${ }^{1}$ Institute of Neuroradiology, University Hospital Zurich, 8091 Zurich, Switzerland, ${ }^{2}$ Department of Urology, Erasmus Medical Center, Erasmus University, Rotterdam, The Netherlands, ${ }^{3}$ Neuro-Urology, Spinal Cord Injury Center \& Research, University of Zurich, Balgrist University Hospital, 8008 Zurich, Switzerland, ${ }^{4}$ Department of Urology, University Hospital Zurich, 8091 Zurich, Switzerland and ${ }^{5}$ Neuro-Urology, Department of Clinical Neurosciences, University Hospital Centre (CHUV), University of Lausanne, 1011 Lausanne, Switzerland
\end{abstract}

${ }^{\dagger}$ Spyros Kollias and Ulrich Mehnert contributed equally and shared senior authorship.

Address correspondence to Ulrich Mehnert, Neuro-Urology, Spinal Cord Injury Center \& Research, University of Zurich, Balgrist University Hospital, Forchstrasse 340, 8008 Zurich, Switzerland. Email: ulrich.mehnert@paralab.balgrist.ch

\begin{abstract}
Despite the crucial role of the brain in the control of the human lower urinary tract, little is known about the supraspinal mechanisms regulating micturition. To investigate the central regulatory mechanisms activated during micturition initiation and actual micturition, we used an alternating sequence of micturition imitation/imagination, micturition initiation, and actual micturition in 22 healthy males undergoing functional magnetic resonance imaging. Subjects able to micturate (voiders) showed the most prominent supraspinal activity during the final phase of micturition initiation whereas actual micturition was associated with significantly less such activity. Initiation of micturition in voiders induced significant activity in the brainstem (periaqueductal gray, pons), insula, thalamus, prefrontal cortex, parietal operculum and cingulate cortex with significant functional connectivity between the forebrain and parietal operculum. Subjects unable to micturate (nonvoiders) showed less robust activation during initiation of micturition, with activity in the forebrain and brainstem particularly lacking. Our findings suggest that micturition is controlled by a specific supraspinal network which is essential for the voluntary initiation of micturition. Once this network triggers the bulbospinal micturition reflex via brainstem centers, micturition continues automatically without further supraspinal input. Unsuccessful micturition is characterized by a failure to activate the periaqueductal gray and pons during initiation.
\end{abstract}

Keywords: functional magnetic resonance imaging, lower urinary tract, micturition, pontine micturition center, supraspinal control

\section{Introduction}

The human lower urinary tract (LUT) is controlled by a complex supraspinal network which permits the voluntary regulation of LUT function, that is, to decide where and when to empty the bladder (Fowler et al. 2008). Loss or impairment of such supraspinal control frequently results in LUT dysfunctions and symptoms which can significantly reduce quality of life, including impairments in sexuality, emotional well-being, and productivity at home and work (Coyne, Sexton, Kopp et al. 2011; Coyne, Sexton, Thompson et al. 2011). Despite this substantial clinical and social importance (Coyne et al. 2009; Fowler, Panicker et al. 2010; Fowler, Dalton et al. 2010; Irwin et al. 2011) and the critical role the brain plays in the control of micturition and urinary continence (Blok and Holstege 1999), little is known about the supraspinal processes and interactions that are involved in micturition events.
Authors working with animals have described neurons in the dorsolateral part of the pontine tegmentum, termed the "pontine micturition center" (PMC) responsible for synergic micturition-a sequence beginning with relaxation of the bladder neck and external urethral sphincter (EUS) and followed by detrusor contraction. (Barrington 1925; Loewy et al. 1979; Blok and Holstege 1996, 1999; de Groat 2006). Other animal studies suggest that micturition is regulated by a spinobulbospinal reflex circuitry with the PMC as the initiator of the efferent reflex arc (Blok and Holstege 1996; de Groat 2006). The PMC, via one long, descending pathway to the sacral spinal cord, controls both the relaxation of the EUS and the contraction of the detrusor, although micturition in healthy humans relies on this reflex circuitry only during early infancy. During brain maturation and social education this reflex is gradually put under suprapontine control (de Groat 2002; de Groat and Wickens 2013).

Recent functional neuroimaging studies have investigated supraspinal LUT control during bladder filling and pelvic floor contractions but little is known about the supraspinal areas and dynamic processes involved in micturition and the voluntary switch-over from urine storage to micturition (Fowler and Griffiths 2010). These are important aspects because it is this voluntary switch that is often impaired in patients with LUT symptoms.

In this study, we investigate supraspinal activity in healthy males during micturition initiation and actual micturition using a series of experimental challenges during blood oxygen leveldependent (BOLD) functional magnetic resonance imaging (fMRI). We were particularly interested in the dynamics of any supraspinal activity and the functional connectivity between activated areas during the switch from storage to micturition.

Our hypotheses were 3-fold:

1. Initiation of micturition requires more cognitive control compared with actual micturition, with the latter considered a spinobulbospinal reflex which, once initiated, continues without the need for further supraspinal input.

2. Initiation of micturition requires, in addition to brainstem regions including the periaqueductal gray (PAG) and pons, the recruitment of interoceptive areas (e.g., the insula, thalamus, and cingulate cortex), areas for maintaining cognitive control (e.g., the prefrontal cortex [PFC]), and for integrating somatosensory and sensorimotor information (e.g., the parietal operculum [OP]). 
3. Supraspinal centers will be functionally more strongly connected during the initiation phase compared with actual micturition, as the former requires orchestrated neural integration in contrast to the reflex-dominated execution of the latter.

This is a prospective, single center fMRI study. Ethical approval was obtained from the local ethics committee. All participating subjects provided written, informed consent.

\section{Materials and Methods}

Right-handed males between the ages of 18-45 years were eligible for inclusion. Exclusion criteria included any urological symptoms, regular medications, known psychological or neurological disorders or contraindication for MRI (e.g., ferromagnetic implants, claustrophobia, cardiac pacemakers). Men meeting the exclusion criterion of pre-existing urological symptoms were identified through a detailed urological history and evaluation using the International Prostate Symptom Score (IPSS).

Forty-five to $60 \mathrm{~min}$ before entering the scanner, all subjects received $20 \mathrm{mg}$ oral furosemide and were advised to drink water until a persistent desire to void developed. Meanwhile, the scanning procedure and instructions were explained to the subjects. A condom catheter was attached to the penis of each subject and connected to a draining tube with an integrated custom-made flow detector calibrated to determine the onset and end of each micturition. The flow detector consisted of 2 copper wires inserted horizontally, $2 \mathrm{~mm}$ apart into the draining tube at the outflow of the condom catheter. Both wires were connected via isolated cables to an ohmmeter outside the scanner room. The ohmmeter reliably recorded the change in impedance between the 2 copper wires caused by the commencement or cessation of urine flow.

Prior to scanning, bladder volume and the level of desire to void were measured using abdominal ultrasound and a visual analog scale (VAS, ranging from $0=$ no desire to void at all to $10=$ strongest urge to void), respectively.

All fMRI measurements were performed in the supine position using a Philips Achieva 3.0 Tesla MR scanner (Philips Medical Systems, Best, the Netherlands) with an 8-channel head coil.
An anatomical scan was acquired for each subject using a 3D, $T_{1}$-weighted gradient echo sequence (time echo [TE]/time repetition $[\mathrm{TR}]=2.3 / 20 \mathrm{~ms}$, field of view $[\mathrm{FOV}]=220 \times 220 \mathrm{~mm}^{2}$, matrix $=256 \times$ 256 , slices $=180$, slice thickness $=0.75 \mathrm{~mm}$ ).

Following automatized, whole-brain shimming, functional, BOLDsensitive images were acquired using a single-shot gradient echo EPI pulse sequence $\left(\mathrm{TE} / \mathrm{TR}=35 / 3000 \mathrm{~ms}\right.$, flip angle $=82^{\circ}, \mathrm{FOV}=220 \times$ $220 \mathrm{~mm}^{2}$, matrix $=128 \times 128$, slices $=39$, slice thickness $=3 \mathrm{~mm}$ ). Sensitivity encoding (Boujraf et al. 2009) with a reduction factor of 2 was used to minimize the influence of susceptibility artefacts and to maximize the possible number of slices acquired within one TR.

The functional experiment consisted of 2 blocks presented in a random order during a $300 \mathrm{~s}$ scanning session (Fig. 1 and Table 1). Block (1) comprised 2 conditions: REST (visual fixation) and IMITATE (subjects visually imagine starting micturition). Block (2) comprised 4 conditions: REST (visual fixation), INITIATE (subjects should start micturition), URINATE (actual micturition, urine is flowing), and STOP (interruption of micturition). The onset of each of the conditions REST, IMITATE, INITIATE, and STOP were defined as the moment the particular visual cues for the respective conditions were presented, while the onset of URINATE was determined by the actual onset of micturition, that is, urine flow was detected by the flow detector (Table 1). The duration of the INITIATE condition was limited to a maximum of $60 \mathrm{~s}$. If micturition could not be initiated during this time, URINATE and STOP were skipped and the next block followed.

The 2 blocks were repeatedly presented in a random order. Each block was repeated at least 8 times and thereafter as many times as possible, with the number of repeats largely dependent on the duration of the INITIATE condition of block (2) (Fig. 1 and Table 1).

During subsequent fMRI analysis, the INITIATE condition was split into an early (INITIATE-E) and a late (INITIATE-L) phase (Table 1) to examine the dynamics of supraspinal activity during INITIATE and to distinguish between the early and late phases of this process.

On completion of scanning, all subjects again rated their desire to void using the VAS. Bladder volume was assessed using abdominal ultrasound and uroflowmetry was performed.

Data analysis, including preprocessing of the imaging data, was performed with SPM5 (Wellcome Trust Centre for Neuroimaging, London, UK). The first 4 scans were removed to allow for longitudinal magnetization equilibrium. For the preprocessing, the following steps were

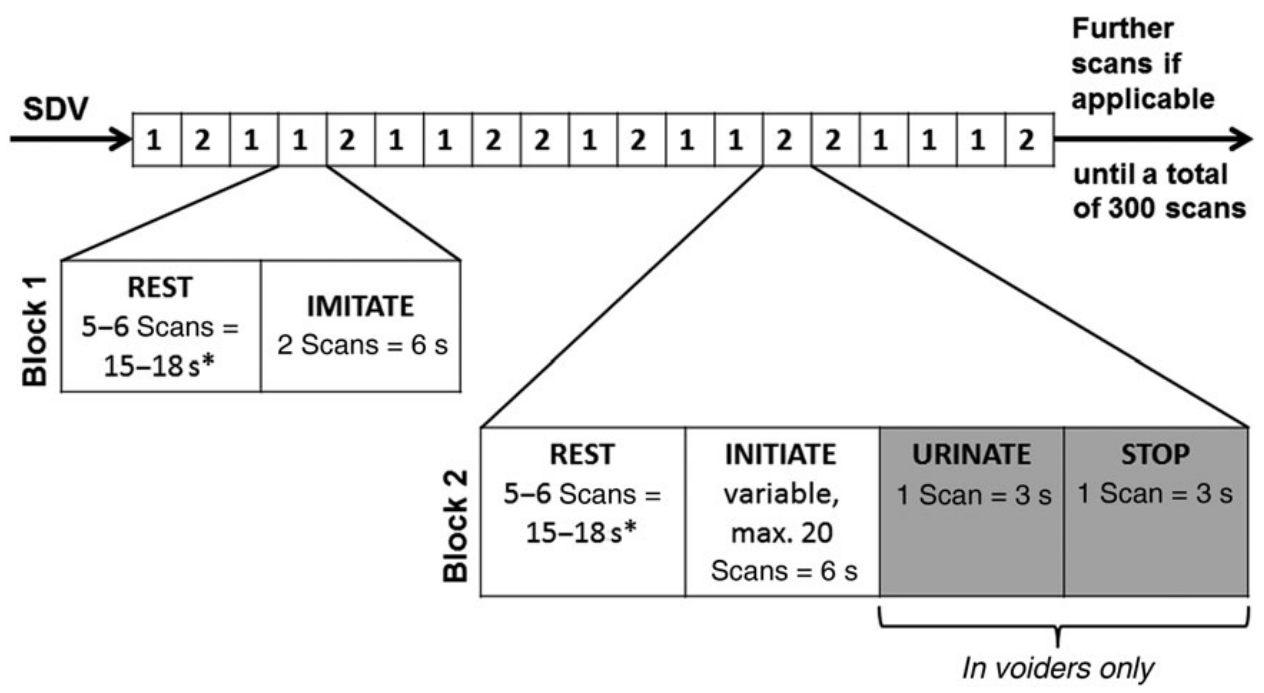

Figure 1. The scan paradigm consisted of 2 randomly alternating blocks. Block (1) comprised 2 conditions: REST (visual fixation) and IMITATE (subjects visually imagine starting micturition). Block (2) comprised 4 conditions: REST (visual fixation), INITIATE (subjects should start micturition), URINATE (actual micturition, urine is flowing), and STOP (=interruption of micturition). The experimental onsets for REST, IMITATE, INITIATE, and STOP were defined by the visual cues presented for each condition, while the onset for URINATE was determined by the actual onset of micturition, when urine flow was first detected by the flow detector. If micturition could not be started during the INITIATE condition, which was limited to a maximum duration of $60 \mathrm{~s}$, URINATE and STOP were skipped and the next block followed immediately, starting with REST. Each block was randomly repeated at least 8 times and as often as possible depending on the duration of the INITIATE condition. The conditions highlighted in gray, that is, URINATE and STOP, were only applicable when actual micturition could be initiated. In nonvoiders, the INITIATE condition was always followed by the REST condition of the subsequent block. SDV, strong desire to void. *REST conditions following INITIATE (in the case of inability to initiate actual micturition) or IMITATE had a duration of $18 \mathrm{~s}$. REST conditions following STOP had a duration of $15 \mathrm{~s}$. 


\begin{tabular}{|c|c|c|c|c|c|}
\hline \multicolumn{6}{|c|}{$\begin{array}{l}\text { Table } 1 \\
\text { Overview of the different functional conditions used in this study }\end{array}$} \\
\hline $\begin{array}{l}\text { Condition } \\
\text { name }\end{array}$ & Condition description & $\begin{array}{l}\text { Condition } \\
\text { duration }\end{array}$ & $\begin{array}{l}\text { No. of repetitions of } \\
\text { each condition }\end{array}$ & Visual cue indicating each condition & $\begin{array}{l}\text { Event-related contrast vectors for the GLM } \\
\text { design matrix of the first-level analysis }\end{array}$ \\
\hline REST & Visual fixation & $15-18 s^{*}$ & $\min .16 \times$ & & Not modeled \\
\hline IMITATE & $\begin{array}{l}\text { Subjects visually imagine } \\
\text { starting to micturate }\end{array}$ & $6 s$ & $\min .8 \times$ & & IMITATE, $6 \mathrm{~s}$ \\
\hline INITIATE & $\begin{array}{l}\text { Subjects attempt to initiate } \\
\text { micturition }\end{array}$ & $\begin{array}{l}\text { Variable, max. } \\
60 \mathrm{~s}\end{array}$ & $\min .8 \times$ & 1 & INITIATE early, $3 \mathrm{~s}$ \\
\hline & & & & & INITIATE late, $3 \mathrm{~s}$ \\
\hline URINATE & $\begin{array}{l}\text { Actual micturition; urine is } \\
\text { flowing }\end{array}$ & $3 \mathrm{~s}$ & As often as possible & $\begin{array}{l}\text { No cue presented; start of URINATE condition was determined } \\
\text { by start of urine flow detected by the flow detector }\end{array}$ & URINATE, $3 \mathrm{~s}$ \\
\hline STOP & Stop micturition & $3 \mathrm{~s}$ & $\begin{array}{l}\text { Only following } \\
\text { successful URINATE }\end{array}$ & & STOP, $3 \mathrm{~s}$ \\
\hline
\end{tabular}

Notes: The conditions URINATE and STOP, were only applicable if micturition could be initiated. In nonvoiders, the INITIATE condition was always followed by the REST condition of the subsequent block. *REST conditions following INITIATE (in the case of inability to initiate micturition) or IMITATE had a duration of $18 \mathrm{~s}$. REST conditions following STOP had a duration of $15 \mathrm{~s}$.

applied: realignment, normalization to the Montreal Neurological Institute (MNI) template, temporal filtering (128 s), and spatial smoothing $(8 \mathrm{~mm})$. A strict head-motion exclusion threshold (translation: $<1.5$ $\mathrm{mm}$ total displacement, rotation: $\left\langle 1^{\circ}\right.$ ) resulted in the exclusion of one subject. For the rest of the subjects, results did not substantially differ whether motion regressors were included in the general linear model (GLM) or not. The design matrix of the GLM for the first-level analysis consisted of the following 5 event-related contrast vectors, used to distinguish supraspinal activity before, during, and after micturition (Table 1): IMITATE (modeling duration: 2 TRs $=6 \mathrm{~s}$ ), early INITIATE (INITIATE-E, initiation onset; modeling duration: one TR $=3 \mathrm{~s}$ ), late INITIATE (INITIATE-L, modeling duration: one TR $=3 \mathrm{~s}$ before micturition), URINATE (modeling duration: one $\mathrm{TR}=3 \mathrm{~s}$, voiders only), and STOP (modeling duration: one $\mathrm{TR}=3 \mathrm{~s}$ following URINATE, voiders only). The reason for the rather short URINATE condition relied on the intention to prevent too much urine loss during a single micturition that may have resulted in a significant decline in bladder volume, a subsequent decreased desire to void and inability to micturate multiple times.

Next, a second-level random effects group analysis was performed to account for between-subject variability. Within-group results are shown at a voxel-threshold of $P<0.001$ using the false discovery rate (FDR) correction (Genovese et al. 2002) or, if they did not survive this threshold, at an uncorrected voxel-threshold of $P<0.01$ with a strict cluster threshold correction of $P<0.01$ (cluster extend: $k>106$ voxels) to correct for multiple comparisons using widely accepted Monte Carlo simulations (Slotnick et al. 2003). Between-group differences were reported at an uncorrected voxel-threshold level of $P<0.05$ with an additional cluster threshold correction of $P<0.01$ (cluster extend: $k=515$ voxel).

For group activations in somatosensory regions, Brodmann areas (BA) were identified using the probability maps in the anatomy toolbox for SPM5 (Eickhoff et al. 2005).

Functional connectivity (FC) analyses between areas activated during initiation of micturition and during actual micturition (voiders only) were performed using the CONN functional connectivity toolbox for SPM (v13i, http://www.nitrc.org/projects/conn/). White matter, cerebrospinal fluid (CSF), and the 6 motion parameters were used as covariates of no interest. Only the white matter and CSF signals were removed to avoid any bias introduced through removing the global signal (i.e., gray matter) (Behzadi et al. 2007; Murphy et al. 2009). This approach allows for the "normalization" of the distribution of voxel-to-voxel connectivity values as effectively as would inclusion of the global signal as a covariate of no interest, but without the potential problems of the latter method. Although we did not record respiration and cardiac responses, it has been demonstrated that nonneuronal physiological noise (e.g., cardiac and respiratory signal) can successfully be removed by the CompCor algorithm (Behzadi et al. 2007), as implemented in the CONN toolbox. Bivariate correlations were calculated as a measure of the strength of functional connectivity, using crosscorrelations of BOLD-signal time series between regions of interest (ROIs). For each individual, fMRI time-series were extracted from each ROI using MarsBaR (Brett et al. 2002; http://marsbar.sourceforge.net/) after the fMRI time-series had been spatially smoothed, temporally filtered $(0.01-0.1 \mathrm{~Hz})$, normalized, and motion-corrected. The signal of a given ROI was then averaged to 4-mm-diameter spheres. ROIs were taken from functional activation peaks during the INITIATE-L condition (Table 3). Statistical analyses for this ROI-ROI approach were performed for 1 ) INITIATE (INITIATE-E + INITIATE-L, $P<0.05$ corrected for multiple comparisons using the FDR correction), 2) URINATE, and 3) for the between-condition contrast "INITIATE-URINATE" $(P<0.001$, uncorrected). For analysis 1), time series of both INITIATE-E and INITIATE-L were concatenated (i.e., trial duration was $6 \mathrm{~s}$ ) to increase the number of time points, thereby increasing the robustness of the statistical analysis

\section{Results}

Twenty-two right-handed, healthy male volunteers with no pre-existing urological symptoms and a mean age of $26.4 \pm 6.2$ years were included (Table 2). The mean IPSS score was $3.1 \pm 2.3$ and all subjects had an IPSS score $\leq 7$ (Table 2).

Prior to scanning, the mean desire to void on the VAS and the mean bladder volume of all subjects was $7.1 \pm 1.3$ and $572.8 \pm 251.0 \mathrm{~mL}$, respectively.

During scanning, 15 subjects were able to micturate (voiders) with a mean frequency of $9.9 \pm 4.3$ (range: $4-15$ ) and a mean total volume of $355 \pm 107 \mathrm{~mL}$ (range: $165-535 \mathrm{~mL}$ ) (Table 2). The mean time needed to start micturition (i.e., the duration of the INITIATE condition) was $19.9 \pm 8.3 \mathrm{~s}$ (Table 2). Seven subjects were not able to micturate (nonvoiders).

After scanning, voiders had a mean desire to void of $4.9 \pm 2.1$ and a mean bladder volume of $915 \pm 363 \mathrm{~mL}$ (Table 2). Nonvoiders had a mean desire to void of $7.7 \pm 1.1$ and a mean bladder volume of $1005 \pm 347 \mathrm{~mL}$ (Table 2 ). The maximum and average flow rate on uroflowmetry was $28.8 \pm 9.9 \mathrm{~mL} / \mathrm{s}$ and $15.8 \pm 5.8 \mathrm{~mL} / \mathrm{s}$ in voiders and $29.4 \pm 10.1$ $\mathrm{mL} / \mathrm{s}$ and $16.3 \pm 5.2 \mathrm{~mL} / \mathrm{s}$ in nonvoiders, respectively (Table 2). 


\begin{tabular}{|c|c|c|c|c|c|c|c|c|c|c|c|c|c|c|c|c|c|c|c|c|}
\hline \multicolumn{6}{|c|}{ Table 2} & & & & & & & & & & & & & & & \\
\hline \multicolumn{2}{|c|}{ Subject } & \multicolumn{2}{|c|}{ Age (years) } & \multicolumn{2}{|c|}{ IPSS } & \multirow{2}{*}{$\begin{array}{l}\text { Number of } \\
\text { successful } \\
\text { micturitions during } \\
\text { fMRl experiment } \\
\text { V only }\end{array}$} & \multirow{2}{*}{$\begin{array}{l}\text { Total voided } \\
\text { volume (mL) } \\
\text { during fMRI } \\
\text { experiment } \\
\text { V only }\end{array}$} & \multirow{2}{*}{$\begin{array}{l}\text { Mean time (s) } \\
\text { required to start } \\
\text { micturition during } \\
\text { fMRl experiment } \\
\text { V only }\end{array}$} & \multicolumn{2}{|c|}{$\begin{array}{l}\text { Desire to void (VAS } \\
0-10) \text { prior to fMRI } \\
\text { experiment }\end{array}$} & \multicolumn{2}{|c|}{$\begin{array}{l}\text { Bladder volume } \\
\text { (mL) prior to fMRI } \\
\text { experiment }\end{array}$} & \multicolumn{2}{|c|}{$\begin{array}{l}\text { Desire to void [VAS } \\
0-10 \text { ] after fMRI } \\
\text { experiment }\end{array}$} & \multicolumn{2}{|c|}{$\begin{array}{l}\text { Bladder volume }(\mathrm{mL}) \\
\text { after fMRI experiment }\end{array}$} & \multicolumn{2}{|c|}{$\begin{array}{l}O_{\max }(\mathrm{mL} / \mathrm{s}) \text { on } \\
\text { uroflowmetry after } \\
\text { fMRI experiment }\end{array}$} & \multicolumn{2}{|c|}{$\begin{array}{l}\mathrm{O}_{\mathrm{ave}}(\mathrm{mL} / \mathrm{s}) \text { on } \\
\text { uroflowmetry after } \\
\text { fMRl experiment }\end{array}$} \\
\hline V & NV & v & NV & V & NV & & & & V & NV & V & NV & V & NV & v & NV & V & NV & V & NV \\
\hline 1 & 1 & 31 & 41 & 0 & 1 & 15 & 425 & 10.6 & 5.2 & 6.6 & 290 & 900 & 1.9 & 6.3 & 354 & 1180 & 26.9 & 10.4 & 15.7 & 6.5 \\
\hline 2 & 2 & 35 & 28 & 2 & 1 & 15 & 355 & 9.8 & 8.5 & 6.5 & 640 & 700 & 6.9 & 8.6 & 1080 & 1109 & 38.8 & 22.9 & 18.8 & 11.3 \\
\hline 3 & 3 & 24 & 33 & 4 & 1 & 13 & 305 & 25.5 & 6.7 & 5.1 & 510 & 515 & 4.2 & 6.2 & 812 & 954 & 22.2 & 40.9 & 13.8 & 21.7 \\
\hline 4 & 4 & 20 & 25 & 4 & 3 & 13 & 345 & 16.3 & 8.2 & 7.9 & 630 & 740 & 4.6 & 9.0 & 892 & 1425 & 35.1 & 42.2 & 20.7 & 21.3 \\
\hline 5 & 5 & 32 & 18 & 4 & 3 & 10 & 400 & 29.6 & 7.4 & 7.6 & 600 & 231 & 8.6 & 9.0 & 1229 & 1354 & 13.2 & 32.8 & 8.9 & 17.3 \\
\hline 6 & 6 & 22 & 18 & 4 & 7 & 12 & 255 & 19.5 & 8.0 & 5.3 & 448 & 200 & 3.7 & 6.9 & 1139 & 445 & 23.3 & 27.1 & 9.3 & 16.1 \\
\hline 7 & 7 & 26 & 27 & 7 & 2 & 8 & 165 & 20.3 & 9.9 & 8.3 & 1091 & 411 & 6.4 & 7.9 & 1091 & 568 & 23.7 & 29.7 & 8.7 & 20.2 \\
\hline 8 & & 21 & & 1 & & 15 & 195 & 34.6 & 8.4 & & 796 & & 6.7 & & 849 & & 34.5 & & 20.9 & \\
\hline 9 & & 31 & & 7 & & 7 & 445 & 14.9 & 6.9 & & 523 & & 6.2 & & 1236 & & 42.1 & & 25.3 & \\
\hline 10 & & 29 & & 7 & & 15 & 535 & 10.3 & 5.8 & & 160 & & 2.9 & & 269 & & 13.7 & & 7.8 & \\
\hline 11 & & 21 & & 3 & & 6 & 490 & 20.1 & 5.3 & & 310 & & 1.6 & & 360 & & 43.3 & & 19.9 & \\
\hline 12 & & 21 & & 5 & & 5 & 420 & 16.8 & 7.0 & & 880 & & 7.2 & & 1244 & & 21.7 & & 10.9 & \\
\hline 13 & & 33 & & 1 & & 4 & 280 & 36.3 & 6.6 & & 429 & & 4.2 & & 1502 & & 31.2 & & 16.5 & \\
\hline 14 & & 21 & & 1 & & 5 & 430 & 14.7 & 7.2 & & 818 & & 3.2 & & 737 & & 40.4 & & 24.7 & \\
\hline $15^{*}$ & & 23 & & 0 & & 6 & 280 & 18.6 & 8.2 & & 779 & & 5.9 & & 937 & & 21.3 & & 15.3 & \\
\hline Mean & & 26.0 & 27.1 & 3.3 & 2.6 & 9.9 & 355 & 19.9 & 7.3 & 6.8 & 594 & 528 & 4.9 & 7.7 & 915 & 1005 & 28.8 & 29.4 & 15.8 & 16.3 \\
\hline $\pm S D$ & & 5.3 & 7.5 & 2.5 & 2.0 & 4.3 & 107 & 8.3 & 1.3 & 1.2 & 251 & 246 & 2.1 & 1.1 & 363 & 347 & 9.9 & 10.1 & 5.8 & 5.2 \\
\hline$t$-test & & $P=0$ & 0.435 & $P$ & & $\mathrm{n} / \mathrm{a}$ & $\mathrm{n} / \mathrm{a}$ & $n / a$ & & 0.990 & $P$ & $=0.782$ & & 0.084 & & 0.877 & & 0.814 & & 0.732 \\
\hline
\end{tabular}

Note: Demographic and urodynamic data of the 22 male volunteers, 15 voiders (V) and 7 nonvoiders (NV).

IPSS, International Prostate Symptom Score; fMRI, functional magnetic resonance imaging: VAS, visual analog scale; $Q_{\text {max }}$ maximum flow rate, $Q_{\text {ave, }}$ average flow rate.

*Subject 15 of the voiders group was excluded from the final fMRI analysis due to significant head motion during the experiment. 
There were no differences between voiders and nonvoiders with respect to age, IPSS, desire to void before and after scanning, bladder volume before and after scanning or maximum and average flow rate (all $P$ values $>0.05$, unpaired $t$-tests) (Table 2).

One of the voiders had to be excluded from fMRI data analysis due to significant head movement in the scanner. The following fMRI results were therefore generated from 14 voiders and 7 nonvoiders.

\section{Activation Patterns}

During IMITATE, both groups of subjects showed activity $(P<$ 0.01 ) in the middle frontal gyrus (MFG), temporal, and cerebellar areas (Table 3). Activity in the inferior frontal gyrus (IFG) was only detected in voiders while activity in the insular cortex and supramarginal gyrus (SMG) was only detected in nonvoiders. Statistical comparison of voiders with nonvoiders did not yield significant differences.

During INITIATE-E, voiders demonstrated significant activity $(P<0.01)$ in the IFG bilaterally, the right insula, and the PAG
(Table 3, Fig. 2). Nonvoiders demonstrated significant activity $(P<0.01)$ only in the cerebellum (Table 3 and Fig. 2$)$. Comparison of both groups did not yield any significant differences.

During INITIATE-L, voiders demonstrated significant BOLDsignal increase $(P<0.001$, FDR corrected) in OP 1 and OP 4 (Eickhoff et al. 2010) and MFG bilaterally, left cerebellum, left thalamus (ventral posterolateral nucleus), left middle temporal gyrus (MTG), left precentral gyrus (PreCG), right posterior cingulate cortex (PCC), right precuneus, and the right pons (Table 3 and Fig. 2). In contrast, nonvoiders had significant BOLD-signal increases $(P<0.01)$ in the superior temporal gyrus (STG) and inferior parietal lobe (IPL) bilaterally, left OP 4, left parahippocampal gyrus (PHG), left anterior midcingulate cortex (aMCC), right posterior midcingulate cortex (pMCC), right PCC, right superior frontal gyrus (SFG), right MTG, and right SMG (Table 3 and Fig. 2). Overall, the level of significance for BOLD-signal increases during INITIATE-L in voiders $(P=0.001)$ was higher than in nonvoiders $(P=0.01)$ and also higher than during IMITATE, INITIATE-E, and URINATE in voiders (Table 3 and Fig. 2).

Table 3

Locations of supraspinal peak activation during the different micturition-related conditions

\begin{tabular}{|c|c|c|c|c|c|c|c|c|c|c|c|c|c|}
\hline \multicolumn{7}{|l|}{ Voiders $(n=14)$} & \multicolumn{7}{|l|}{ Nonvoiders $(n=7)$} \\
\hline \multirow[t]{2}{*}{ Region } & \multirow[t]{2}{*}{$\mathrm{BA}$} & \multirow[t]{2}{*}{ HEM } & \multirow[t]{2}{*}{$t$-value } & \multicolumn{3}{|c|}{ MNI coordinates (mm) } & \multirow[t]{2}{*}{ Region } & \multirow[t]{2}{*}{ BA } & \multirow[t]{2}{*}{ HEM } & \multirow[t]{2}{*}{$t$-value } & \multicolumn{3}{|c|}{ MNI coordinates (mm) } \\
\hline & & & & $x$ & $y$ & $z$ & & & & & $x$ & $y$ & $z$ \\
\hline \multicolumn{14}{|c|}{ IMITATE } \\
\hline \multicolumn{14}{|c|}{$P<0.01$ cluster-corrected, $k>106$} \\
\hline IFG & 46 & $\mathrm{LH}$ & 4.13 & -48 & 45 & 3 & СT & $\mathrm{n} / \mathrm{a}$ & $\mathrm{LH}$ & 3.98 & -36 & -75 & -30 \\
\hline MFG & 10 & $\mathrm{LH}$ & 4.66 & -45 & 48 & -9 & MTG & 21 & $\mathrm{RH}$ & 6.18 & 57 & -51 & 3 \\
\hline STG (temporopolar) & 38 & $\mathrm{LH}$ & 5.00 & -54 & 12 & -9 & STG (temporopolar) & 38 & $\mathrm{RH}$ & 4.61 & 57 & 15 & -6 \\
\hline CT & $\mathrm{n} / \mathrm{a}$ & $\mathrm{LH}$ & 4.64 & -36 & -57 & -36 & SMG & 40 & $\mathrm{RH}$ & 4.56 & 51 & -48 & 30 \\
\hline $\mathrm{CT}$ & $\mathrm{n} / \mathrm{a}$ & $\mathrm{RH}$ & 4.39 & 42 & -57 & -33 & MFG & 47 & $\mathrm{RH}$ & 4.5 & 48 & 45 & -9 \\
\hline STG (temporopolar) & 38 & $\mathrm{RH}$ & 3.89 & 57 & 12 & -6 & Insula & 13 & $\mathrm{RH}$ & 4.31 & 38 & 15 & 9 \\
\hline \multicolumn{14}{|c|}{ INITIATE-E } \\
\hline \multicolumn{14}{|c|}{$P<0.01$ cluster-corrected, $k>106$} \\
\hline IFG & 45 & $\mathrm{LH}$ & 3.00 & -33 & 24 & 3 & Cerebellum & $\mathrm{n} / \mathrm{a}$ & $\mathrm{LH}$ & 3.36 & -18 & -36 & -24 \\
\hline brainstem/PAG & $\mathrm{n} / \mathrm{a}$ & $\mathrm{LH}$ & 2.90 & -6 & -15 & -6 & & & & & & & \\
\hline IFG & 45 & $\mathrm{RH}$ & 3.39 & 63 & 18 & 18 & & & & & & & \\
\hline Insula (anterior) & 13 & $\mathrm{RH}$ & 3.31 & 36 & 18 & 9 & & & & & & & \\
\hline \multicolumn{14}{|l|}{ INITIATE-L } \\
\hline \multicolumn{7}{|c|}{$P<0.001$ (FDR corrected), cluster-corrected, $k>106$} & \multicolumn{7}{|c|}{$P<0.01$ cluster-corrected, $k>106$} \\
\hline PoCG (OP 1) & 40 & $\mathrm{LH}$ & 6.67 & -57 & -27 & 18 & PoCG (OP 4) & 43 & $\mathrm{LH}$ & 4.85 & -63 & -12 & 18 \\
\hline CT & $\mathrm{n} / \mathrm{a}$ & $\mathrm{LH}$ & 5.15 & -42 & -51 & -39 & $\mathrm{PHG}$ & 30 & $\mathrm{LH}$ & 3.34 & -18 & -51 & 0 \\
\hline Thalamus (VPL) & $\mathrm{n} / \mathrm{a}$ & $\mathrm{LH}$ & 4.77 & -18 & -18 & 6 & aMCC (ROI 6) & 24 & $\mathrm{LH}$ & 3.34 & -6 & 9 & 27 \\
\hline MTG & 37 & $\mathrm{LH}$ & 5.37 & -51 & -63 & 3 & IPL & 40 & $\mathrm{LH}$ & 4.43 & -41 & -36 & 48 \\
\hline MFG & 9 & $\mathrm{LH}$ & 5.29 & -30 & 30 & 36 & STG & 22 & $\mathrm{LH}$ & 4.59 & -57 & 0 & 0 \\
\hline PreCG & 6 & $\mathrm{LH}$ & 4.8 & -57 & 6 & 14 & pMCC (ROI 8) & 6 & $\mathrm{RH}$ & 3.24 & 3 & -12 & 51 \\
\hline MFG & 47 & $\mathrm{RH}$ & 7.29 & 48 & 45 & -6 & STG (temporopolar) & 38 & $\mathrm{RH}$ & 5.95 & 48 & 12 & -18 \\
\hline PoCG (OP 4) & 40 & $\mathrm{RH}$ & 7.18 & 63 & -18 & 18 & PCC (ROI 12) & 30 & $\mathrm{RH}$ & 3.68 & 24 & -60 & 6 \\
\hline PCC (ROI 10) & 31 & $\mathrm{RH}$ & 5.51 & 12 & -30 & 42 & SFG & 10 & $\mathrm{RH}$ & 5.54 & 36 & 54 & 24 \\
\hline Pons (PMC) & $\mathrm{n} / \mathrm{a}$ & $\mathrm{RH}$ & 5.48 & 6 & -30 & -24 & SFG & 9 & $\mathrm{RH}$ & 4.35 & 18 & 54 & 24 \\
\hline \multirow[t]{3}{*}{ Precuneus } & 7 & $\mathrm{RH}$ & 4.59 & 15 & -72 & 48 & MTG & 21 & $\mathrm{RH}$ & 4.48 & 63 & -51 & 3 \\
\hline & & & & & & & $\mathrm{IPL}$ & 40 & $\mathrm{RH}$ & 5.01 & 63 & -39 & 24 \\
\hline & & & & & & & SMG & 40 & $\mathrm{RH}$ & 4.59 & 54 & -48 & 18 \\
\hline \multicolumn{14}{|c|}{ URINATE } \\
\hline \multicolumn{14}{|c|}{$P<0.01$ cluster-corrected, $k>106$} \\
\hline CT & n/a & $\mathrm{RH}$ & 3.47 & 30 & -57 & -45 & & & & & & & \\
\hline STOP & & & & & & & & & & & & & \\
\hline$P<0.01$ cluster-correc & $>10$ & & & & & & & & & & & & \\
\hline ACC & 32 & $\mathrm{LH}$ & 4.99 & -12 & 42 & 6 & & & & & & & \\
\hline Cerebellum & $\mathrm{n} / \mathrm{a}$ & $\mathrm{LH}$ & 3.57 & -3 & -42 & -9 & & & & & & & \\
\hline PAG & $\mathrm{n} / \mathrm{a}$ & $\mathrm{RH}$ & 3.57 & 3 & -27 & -15 & & & & & & & \\
\hline
\end{tabular}

Notes: The supraspinal foci of BOLD-signal increase during the different conditions compared with REST within both groups, (voiders and nonvoiders). In voiders all 5 conditions (IMITATE, INITIATE-E, INITIATE-L, URINATE, and STOP) were applicable, whereas in nonvoiders only 3 conditions (IMITATE, INITIATE-E, and INITIATE-L) were applicable.

The specifications relating to ROI (region of interest) determination in cingulate cortex areas is based on the study of Torta and Cauda (2011).

ACC, anterior cingulate cortex; aMCC, anterior midcingulate cortex; BA, Brodmann area; CT, cerebellar tonsil; HEM, hemisphere; IFG, inferior frontal gyrus; LH, left hemisphere; IPL, inferior parietal lobe; MFG, middle frontal gyrus; MNI, Montreal Neurological Institute; MTG, middle temporal gyrus; OP, parietal operculum; PAG, periaqueductal gray; PCC, posterior cingulate cortex; PHG, parahippocampal gyrus; PMC, pontine micturition center; pMCC, posterior midcingulate cortex; PoCG, postcentral gyrus; PreCG, precentral gyrus; RH, right hemisphere; SMG, supramarginal gyrus; STG, superior temporal gyrus; VPL, ventral posterolateral nucleus. 

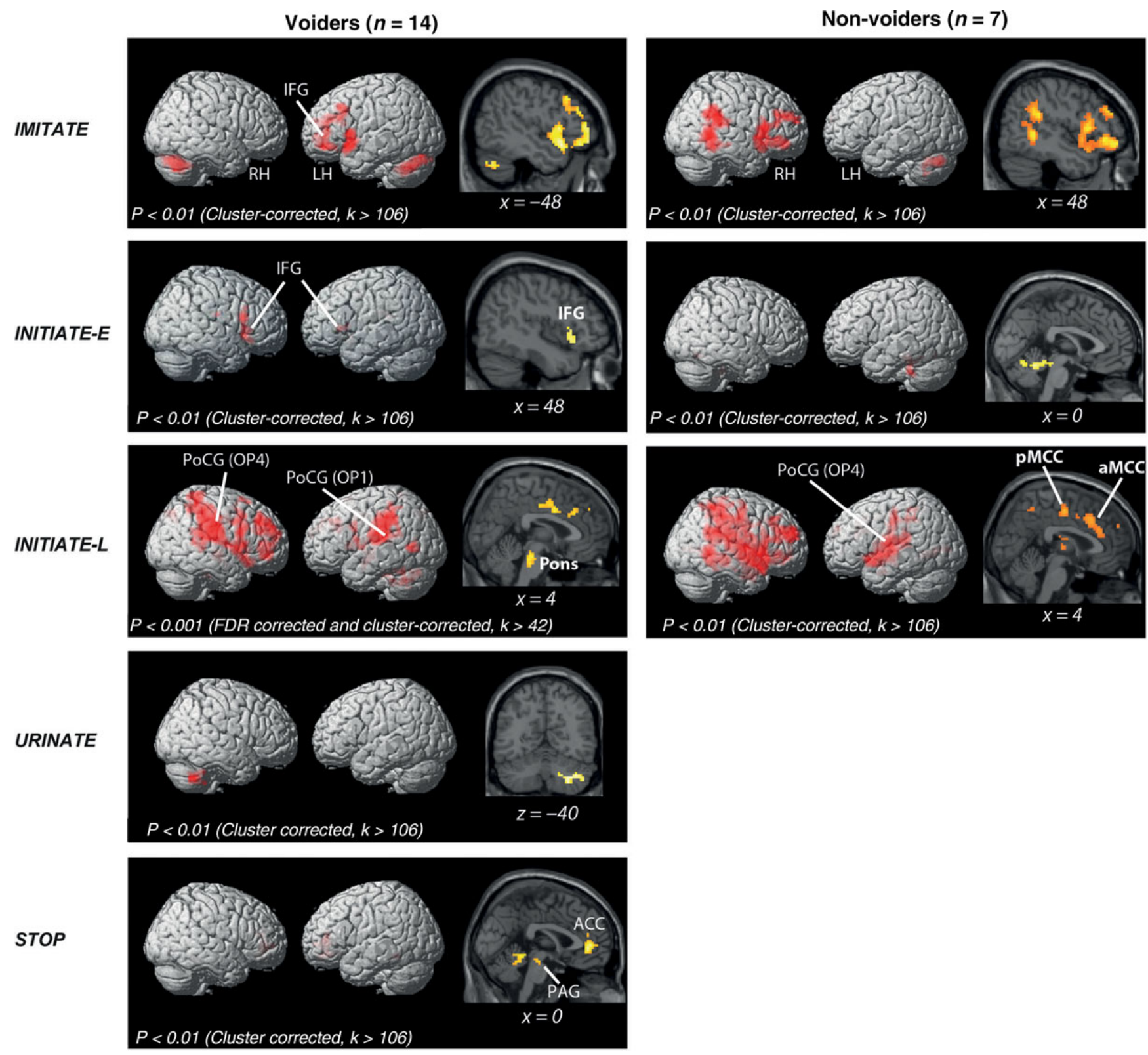

Figure 2. Rendered brain displaying BOLD-signal peaks during different conditions (IMITATE, INITIATE-E, INITIATE-L, URINATE, and STOP) compared with REST in subjects who were able (voiders) and those unable (nonvoiders) to void during scanning. ACC, anterior cingulate cortex; LH, left hemisphere; RH, right hemisphere; IFG, inferior frontal gyrus; PAG, periaqueductal gray; PoCG, postcentral gyrus; OP, parietal operculum; aMCC, anterior midcingulate cortex; pMCC, posterior midcingulate cortex.

The contrast of voiders versus nonvoiders showed voiderspecific BOLD-signal increases in the right PCC and pMCC, right OP 1 and OP 4, right PAG, left cerebellum, and pons (Table 4 and Fig. 3). The contrast nonvoiders versus voiders did not yield significant differences.

During URINATE, voiders demonstrated significant activity $(P<0.01)$ only in the cerebellum (Table 3 and Fig. 2$)$.

Interrupting micturition (STOP condition) in voiders demonstrated significant activation in the PAG, anterior cingulate cortex (ACC), and cerebellum (Table 3 and Fig. 2).

\section{BOLD-Signal Changes in the Pons}

In voiders, BOLD signal response in the pons $(6,-30,-24)$ for each condition showed the strongest increase during the INITIATE-L condition (Fig. 4a). BOLD responses during
IMITATE and URINATE were negative and around zero, respectively (Fig. 4a).

Fitted BOLD-signal responses of individual voiders plotted over the entire measurement demonstrated BOLD signal peaks only during INITIATE-L, which correlated with the number of successful micturitions (Fig. $4 b, c$ ). Nonvoiders generally did not show modulated BOLD responses in the pons during INITIATE-L.

\section{Functional Connectivity Analysis}

The findings of the FC analysis are summarized in Figure 5. Voiders showed a strong positive coupling (red lines) between almost all areas activated during INITIATE (except for the left MFG) at a high statistical threshold $(P<0.05$, FDR corrected, Fig. 5A), including cortical (e.g., right MFG), and sub-cortical 
(e.g., PMC) regions. In contrast, these areas were only moderately strongly connected during URINATE (PCC-precuneus, OP4, and MTG; OP1-OP4, MTG). The between-condition contrast "INITIATE-URINATE" $(P<0.001$, uncorrected $)$ revealed a stronger inter-regional coupling during the initiation of micturition between the OP1/OP4 areas and the MFG, thalamus, and MTG (OP 1 only). The only coupling during urination that was stronger than during initiation (blue line) was that between the left MFG and the cerebellar tonsil (CT).

\section{Discussion}

The results of this study have afforded several novel insights into the control of micturition. Firstly, in voiders, supraspinal activity, including in the pons, is most prominent just before micturition and subsides once actual micturition has started. Secondly, initiation of micturition in voiders induces significant activity in the brainstem, insula, thalamus, PFC, OP, and cingulate cortex. Thirdly, inter-regional coupling is significantly stronger during initiation of micturition than during actual micturition, especially between the OP, MFG, and thalamus.

In addition, we observed that nonvoiders demonstrate reduced supraspinal activity in both the aforementioned cortical network and in brainstem regions, that is, the pons and PAG, compared with voiders.

\begin{tabular}{|c|c|c|c|c|c|c|}
\hline \multicolumn{7}{|c|}{$\begin{array}{l}\text { Table } 4 \\
\text { Differences in supraspinal peak activation between voiders and nonvoiders }\end{array}$} \\
\hline \multirow[t]{2}{*}{ Region } & \multirow[t]{2}{*}{$\mathrm{BA}$} & \multirow[t]{2}{*}{ HEM } & \multirow[t]{2}{*}{$t$-value } & \multicolumn{3}{|c|}{ MNI coordinates (mm) } \\
\hline & & & & $x$ & $y$ & $z$ \\
\hline \multicolumn{7}{|c|}{ INITIATE-L } \\
\hline $\begin{array}{l}\text { Cerebellum (culmen) } \\
\text { Pons (PMC) } \\
\text { Pons (PMC) } \\
\text { pMCC (ROI 8) } \\
\text { PCC (ROI 10) } \\
\text { PoCG (OP1) } \\
\text { PAG } \\
\text { PoCG (OP 4) }\end{array}$ & $\begin{array}{l}\mathrm{n} / \mathrm{a} \\
\mathrm{n} / \mathrm{a} \\
\mathrm{n} / \mathrm{a} \\
24 \\
31 \\
2 \\
\mathrm{n} / \mathrm{a} \\
3\end{array}$ & $\begin{array}{l}\mathrm{RH} \\
\mathrm{RH} \\
\mathrm{RH} \\
\mathrm{RH} \\
\mathrm{RH}\end{array}$ & $\begin{array}{l}2.99 \\
3.13 \\
3.12 \\
4.25 \\
3.72 \\
2.20 \\
2.21 \\
2.4\end{array}$ & $\begin{array}{r}-3 \\
-6 \\
0 \\
18 \\
21 \\
41 \\
9 \\
60\end{array}$ & $\begin{array}{r}-54 \\
-27 \\
-27 \\
-9 \\
-36 \\
-21 \\
-26 \\
-15\end{array}$ & $\begin{array}{r}-9 \\
-21 \\
-27 \\
42 \\
36 \\
30 \\
-5 \\
21\end{array}$ \\
\hline
\end{tabular}

Notes: A comparison of the supraspinal foci of BOLD-signal increase in voiders and nonvoiders During INITIATE-L, BOLD-signal increases were significantly higher at the indicated locations in voiders compared with nonvoiders. The other conditions, IMITATE and INITIATE-E, did not reveal significant differences between voiders and nonvoiders.

The specifications relating to $\mathrm{ROI}$ (region of interest) determination in cingulate cortex areas is based on the study of Torta and Cauda (2011). BA, Brodmann area; HEM, hemisphere; LH, left hemisphere; MNI, Montreal Neurological Institute; OP, parietal operculum; PAG, periaqueductal gray; PCC, posterior cingulate cortex; PMC, pontine micturition center; pMCC, posterior midcingulate cortex; $\mathrm{PoCG}$, postcentral gyrus; $\mathrm{RH}$, right hemisphere.

\section{The Supraspinal Cycle of Micturition and the Bulbospinal Micturition Reflex}

In accordance with our first hypothesis, we observed stronger supraspinal activations during initiation than during actual micturition. This finding can be explained by the increased neuronal recruitment and cognitive effort necessary to initiate micturition. Voluntary control of micturition including its initiation usually requires 4 elements; 1 ) conscious bladder sensation, 2) assessment and integration of environmental, emotional, and social aspects, that is, it is safe, appropriate, and comfortable to micturate, 3) release of the bulbospinal micturition reflex, and 4) adequate sensorimotor function to relax the EUS and pelvic floor muscles (Holstege 2005; Fowler et al. 2008; de Groat and Wickens 2013). In line with these notions, the supraspinal activity we observed included structures involved in 1) interoception, that is, the right anterior insula, PAG, ventral posterior thalamic nucleus (Craig 2002), 2) decision-making, social judgment, and emotional/motivational processing, that is, the IFG, MFG, and the cingulate cortex (Rolls and Grabenhorst 2008; Torta and Cauda 2011), 3) execution of the bulbospinal micturition reflex, that is, the pons (de Groat and Wickens 2013), and 4) sensorimotor control, that is, the precentral gyrus, OP, cingulate cortex, and cerebellum (Eickhoff et al. 2010; Torta and Cauda 2011; Manto and Oulad Ben Taib 2013).

In contrast to initiation, micturition itself was associated with little supraspinal activity, with significant activity only present in the cerebellum. This observation is in keeping with the reflex-like nature of the micturition process which, once released by supraspinal centers, continues at a spinal level without requiring further supraspinal input. Brain-lesioning and electrophysiological studies in cats have revealed that the micturition is reflex-like mediated by a spinobulbospinal circuitry, the ascending limb of which projects from the sacral spinal cord to the pons, which thereupon sends excitatory signals via the descending limb back to the sacral spinal cord, resulting in micturition (de Groat and Wickens 2013). In this context, it is noteworthy that the localization of peak pontine activation in voiders corresponds well to the dorsomedial pontine activation described as the PMC in previous PET studies of micturition (Table 5). This supports the hypothesis that neurons in the dorsomedial pons of humans have a facilitatory function with respect to micturition similar to that described in cats and other vertebrates (Blok and Holstege 1996, 1999).

Our results are, in many aspects, comparable to those of a recent fMRI study investigating the brain switching circuits

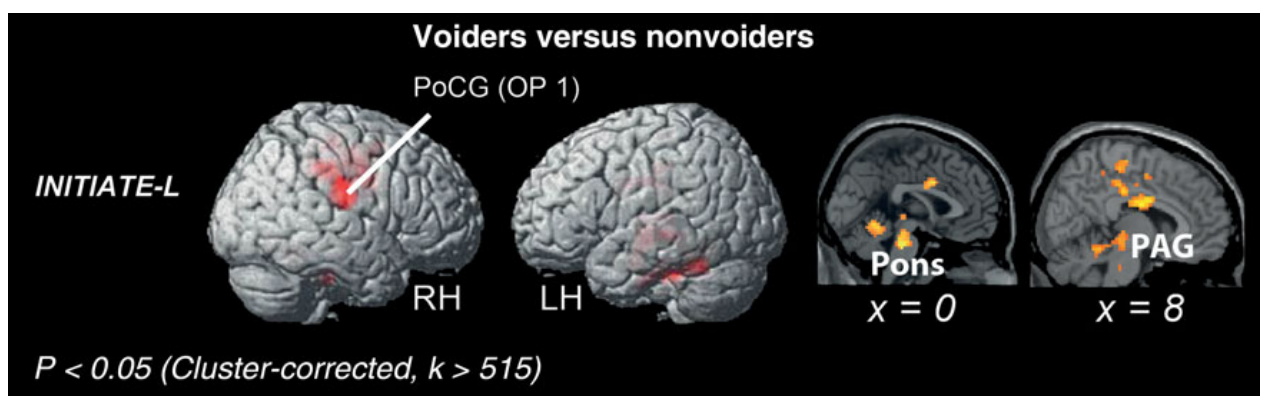

Figure 3. Rendered brain displaying BOLD-signal peaks of voiders versus nonvoiders. LH, left hemisphere; RH, right hemisphere; PoCG, postcentral gyrus; OP, parietal operculum; PAG, periaqueductal gray. 
(a)

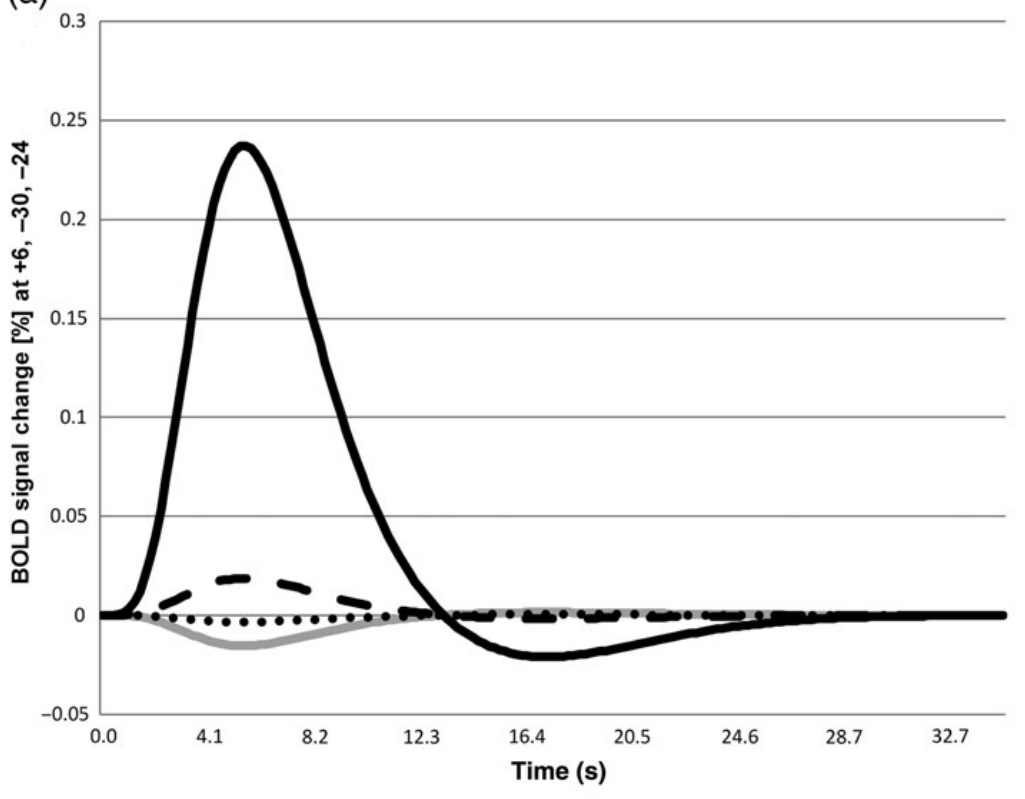

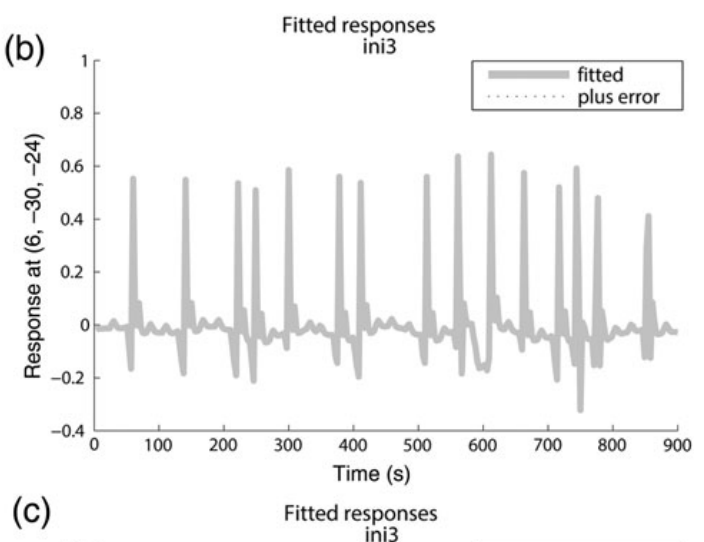

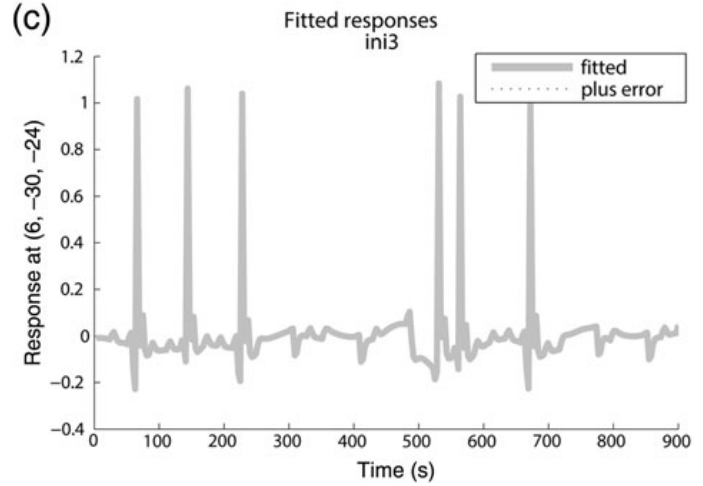

Figure 4. BOLD-signal changes in the pons $(6,-30,-24)$ of voiders during different micturition-related conditions, that is, IMITATE (gray line), INITIATE-E (dashed line), INITIATE-L (black line), URINATE (dotted line) (a). Fitted BOLD responses in the pons $(6,-30,-24)$ during INITIATE-L of a single subject who was able to micturate 15 times over the course of the experiment $(b)$. Fitted BOLD responses in the pons $(6,-30,-24)$ during INITIATE-L of a single subject who was able to micturate 6 times in the course of the experiment $(c)$.

controlling reflex micturition in anesthetised rats (Tai et al. 2009). While urinary storage was associated with an inactive PMC, switching to micturition when the bladder volume approached the reflex micturition threshold was associated with enhanced PMC activity (Tai et al. 2009). In our study, significant PMC activity in voiders was observed only a short time prior to micturition onset. This suggests that the PMC plays an essential role in the final step of the initiation process, instigating the switch from storage to actual micturition. In this experiment, in cases in which the PMC could not be activated within the given time frame, no micturition occurred (Fig. $4 b, c$ ).

In line with the current understanding of the neural control of bladder contraction which is, once triggered by the PMC, exclusively driven by parasympathetic input from S2-S4 and not amenable to voluntary interruption, only a voluntarily induced contraction of the EUS can interrupt micturition via reverse spinal feedback to the detrusor (Blok 2002; de Groat and Wickens 2013). Recent neuroimaging studies of repetitive pelvic floor contractions (mimicking the interruption of micturition), often showed evidence of supplementary motor area (SMA, BA 6) activation (Zhang et al. 2005; Di Gangi Herms et al. 2006; Seseke et al. 2006; Kuhtz-Buschbeck et al. 2007). Neither SMA, nor other motor cortex activity, was present at the threshold of $P<0.01$ (cluster corrected, $k>106$ ) in our study, something probably attributable to differences in the applied protocol. Several of these previous studies used protocols with iterant blocks of repetitive contractions over several seconds (15-32 s) (Zhang et al. 2005; Kuhtz-Buschbeck et al. 2007) or continuous contraction over 2-3 s, repeated 15-33 times (Di Gangi Herms et al. 2006; Seseke et al. 2006). In our experiment, the STOP condition involved a single, short EUS contraction, which was probably insufficient to elicit a significant motor fMRI response, even when the STOP condition was modeled with a duration of $18 \mathrm{~s}$ (STOP plus subsequent REST condition; data not shown).

Nevertheless, during interruption of actual micturition we observed activity in the cerebellum, another area related to motor control (Manto and Oulad Ben Taib 2013). Although previous studies have reported cerebellar activity in response to different LUT conditions, its role in micturition control is unclear. Demonstration of fiber connections from the LUT to the cerebellum (Sakakibara et al. 2004) and its numerous connections to many other parts of the central nervous system, including areas involved in micturition control, lead to the hypothesis that it serves as a modulatory center for various responses, for example, to a full bladder (Dietrichs and Haines 2002). Patients with cerebellar lesions frequently present with abnormal LUT function, including not only EUS dyscoordination and delayed initiation of micturition but also urgency incontinence and detrusor overactivity (Sakakibara et al. 2004; Chou et al. 2013). Urodynamic studies in animals following removal of the cerebellum reported both inhibitory and facilitatory effects on micturition (Dietrichs and Haines 2002; Sakakibara et al. 2004). Such a bidirectional modulatory function of the cerebellum on EUS coordination is supported by the cerebellar activity observed shortly before micturition, during actual micturition, and during interruption of micturition in voiders.

The PAG and ACC activity observed in voiders during the STOP condition probably represents LUT sensory processing in response to micturition interruption. Both areas have frequently been implicated in LUT interoceptive processes during 

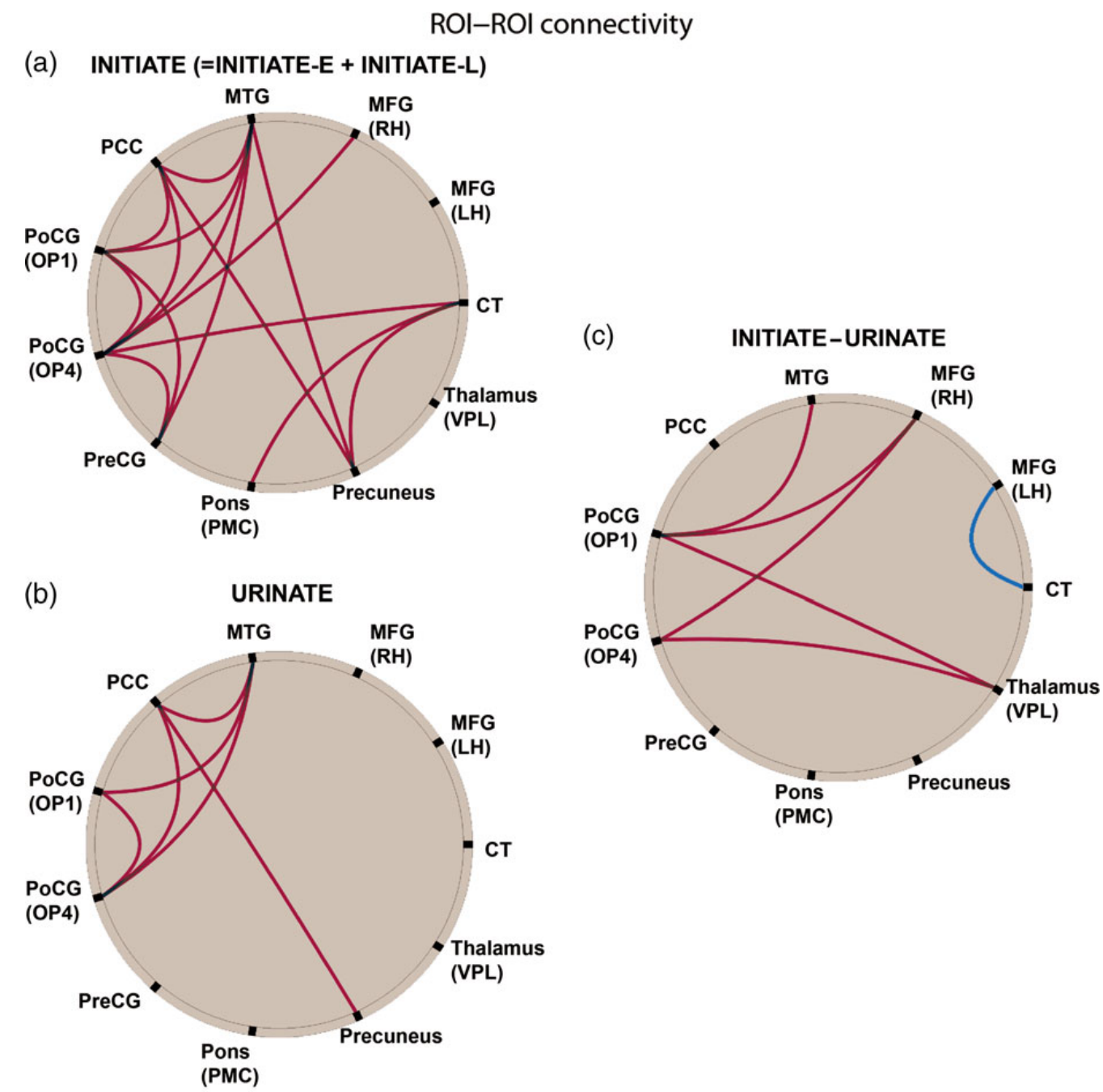

Within conditions
$(P<0.05$ FDR corrected $)$

\section{Between conditions \\ $(P<0.001$ uncorrected $)$}

Figure 5. Summary of the functional connectivity (FC) analysis for voiders. FC during INITIATE (=INITIATE-E + INITIATE-L, $P<0.05$, FDR corrected) (a). FC during URINATE $(P<0.05$, FDR corrected) $(b)$. FC for the contrast "INITIATE-URINATE" $(P<0.001$, uncorrected) $(c)$. The red lines indicate that coupling between connected areas was significantly stronger for the contrasts INITIATE versus REST, URINATE versus REST, and INITIATE versus URINATE. The blue line indicates a significantly stronger coupling between left MFG and CT for the contrast URINATE versus INITIATE. CT, cerebellar tonsil; LH, left hemisphere; MFG, middle frontal gyrus; MTG, middle temporal gyrus; OP, parietal operculum; PCC, posterior cingulate cortex; PMC, pontine micturition center; PoCG, postcentral gyrus; PreCG, precentral gyrus; RH, right hemisphere; VPL, ventral posterolateral nucleus.

Table 5

Activation foci in the pontine micturition center from the previous literature

\begin{tabular}{lllccc} 
Author & Year & Method & \multicolumn{3}{c}{ MNl coordinates $(\mathrm{mm})$} \\
\cline { 4 - 6 } & & & $X$ & $Y$ & $Z$ \\
\hline Fukuyama et al. & 1996 & SPECT & 9 & -20 & -25 \\
Blok et al. & 1997 & PET & 12 & -46 & -27 \\
Blok et al. & 1998 & PET & 18 & -44 & -32 \\
Nour et al. & 2000 & PET & 3 & -38 & -37 \\
Our study & 2013 & fMRI & 6 & -30 & -24 \\
\hline
\end{tabular}

Notes: The coordinates of the activation foci of the pontine micturition center reported in human neuroimaging studies during actual micturition. Coordinates originally given as Talairach coordinates have been converted to MNI coordinates. SPECT, single photon emission computed tomography; $\mathrm{PET}$, positron emission tomography; $\mathrm{fMRl}$, functional magnetic resonance imaging

urinary storage and bladder filling (Fowler and Griffiths 2010). However, interruption of micturition by EUS contraction is a strong inhibitor of the micturition reflex at the spinal cord level through increased pudendal afferent firing. In turn, such pudendal stimulation affects supraspinal sensory processing, manifested as decreased desire to void (Burgio et al. 1998; Mehnert et al. 2008). This might explain the rather moderate increase in PAG and ACC activity and the lack of significant activity in other areas of LUT interoception such as the insula, thalamus, and OP1.

\section{Supraspinal Initiation of Micturition}

Our findings are also supportive of our second hypothesis, in that initiation of micturition involves several supraspinal areas beyond the brainstem. In the healthy state, initiation of micturition requires a voluntary decision and subsequent neuronal implementation. An area frequently associated with decisionmaking and executive function is the PFC. Clinical observations (Ueki 1960; Andrew and Nathan 1964) in patients with loss of voluntary micturition control due to forebrain lesions indicated an important role for the PFC in the control of micturition. Recent animal (Yamamoto et al. 2010; Nishijima et al. 
2012) and PET studies in healthy humans (Blok et al. 1997, 1998; Nour et al. 2000) have also demonstrated significant PFC involvement in micturition control. We observed bilateral IFG activity during INITIATE-E and bilateral MFG activity during INITIATE-L. In our study, the BOLD signal changes in the MFG and IFG were in regions similar to those observed in prior PET micturition studies (Fukuyama et al. 1996; Blok et al. 1997, 1998; Nour et al. 2000). However, it remains unclear whether the PFC inhibits or excites the micturition process or indeed has both functions. Clinical observations support the assumption that the PFC has a predominantly inhibitory function, as lesions in this region tend to lead to urinary urgency and urge incontinence, possibly due to premature or disinhibited release of the micturition reflex (Andrew and Nathan 1964; Sakakibara et al. 1996, 1999). Animal studies suggest that there are both excitatory and inhibitory micturition neurons distributed within the PFC (Yamamoto et al. 2010; Nishijima et al. 2012). This would be in line with the notion that activation of the PFC is specifically relevant to deciding whether or not to start micturition (Blok 2002; Kavia et al. 2005). The PFC is unlikely, however, to be an isolated decision center-more likely it is part of a network that not only processes sensory evidence to compute a decision but also translates this evidence into an action, that is, micturition (Heekeren et al. 2008). Parietal and prefrontal areas in particular (activated in voiders), have been described as important components in perceptual decisionmaking (Heekeren et al. 2008; Kable and Glimcher 2009).

The frontoparietal areas activated in voiders during micturition initiation; the superior dorsal and inferior parietal lobes, IFG, MFG, and anterior insula, correspond to several core components of the proposed ventral and dorsal frontoparietal networks, with the former involved in interruption and resetting of ongoing activity and the latter selecting and linking stimuli and responses (Corbetta et al. 2008).

We observed parietal activity during INITIATE-L in voiders in OP1 and OP4. OP1 is implicated in interoception and has dense connections to both anterior parietal and thalamic areas, including the VPL. It is also associated with the integrative aspects of somatosensory processing (Eickhoff et al. 2010) that may include processing of feedback information from the pelvic floor muscles and EUS. OP4 has sensorimotor functions with connections to frontal and primary sensorimotor areas that support basic sensorimotor processing and action control functions (Eickhoff et al. 2010) such as relaxation of the pelvic floor musculature and the EUS in preparation to pass urine. Indeed, we found significant FC of OP4 to the MFG, preCG, and CT, reflecting the sensorimotor involvement of OP4 in micturition initiation. Moreover, significantly stronger FC was observed between MFG and OP1/OP4 during initiation, as compared with micturition, suggesting that frontoparietal interactions are important for switching from storage to micturition.

Another relevant structure for micturition control is the cingulate cortex. It is considered important for not only the sensorimotor, but also emotional and motivational, aspects of micturition (Fowler and Griffiths 2010; Torta and Cauda 2011). We found significant PCC activity in voiders during INITIATE-L, similar to the findings of a previous study in healthy women with full bladders interpreted as motivational representation of bladder fullness, to prompt emptying of the bladder before becoming too full (Dasgupta et al. 2005). Our connectivity analysis demonstrated significant interactions of the PCC with several areas including OP1 and 4 during INITIATE-L, indicating that tight coupling and information flow between the cingulate and somatosensory cortices may be necessary for initiating micturition.

\section{Supraspinal Functional Connectivity}

In line with our third hypothesis, we observed significantly stronger inter-regional coupling during initiation of micturition compared with actual micturition, mainly driven by the stronger FC between OP, MFG, and thalamus during initiation of micturition (Fig. 5c). This finding strongly indicates that the frontoparietal network plays an important role in the neural orchestration of micturition initiation.

The only functional coupling that was significantly stronger during micturition with respect to initiation was seen between the left MFG and the cerebellum. Based on the aforementioned functional properties of the MFG and cerebellum, that is, planning, decision-making and a modulatory function on EUS coordination, this finding may reflect the planning of EUS contraction required for ceasing micturition.

\section{Differences Between Voiders and Nonvoiders}

Nonvoiders, as compared with voiders, lack significant pontine, that is, PMC, activity during INITIATE-E and INITIATE-L. In accordance with the known function of the PMC, this finding is expected and probably causative of the unsuccessful attempt to micturate. However, lacking PMC activity may well be only the final element of an activation cascade not initiated in nonvoiders. Nonvoiders demonstrated considerably lower BOLDsignal changes than voiders during INITIATE-L and had significantly less activity in the cingulate (PCC and pMCC) and parietal (OP1 and 4) cortices-both areas implicated in micturition facilitation by the FC results in voiders. Interestingly, nonvoiders, in contrast to voiders, demonstrated some aMCC activity. A very similar aMCC area has been described in women with chronic urinary retention due to EUS overactivity of unknown origin (Dasgupta et al. 2005). This finding is suggestive of an inhibitory effect of the aMCC on micturition-facilitating structures such as the PMC and PAG. This interpretation is supported by the findings of Dasgupta et al. (2005) who demonstrated the abolition of aMCC activity following sacral neuromodulation resulting in successful micturation, and observed that previously absent midbrain activity became significant. Altered emotional and/or motivational processing linked to the cingulate cortex and related to the experimental setting may have affected the ability of the nonvoiders in our study to micturate, since all subjects were able to empty their bladder without difficulty outside the scanner.

\section{In Summary}

In summary, our fMRI study demonstrates that activation of a specific supraspinal network incorporating prefrontal, parietal, and cingulate areas is required to successfully initiate micturition. Once micturition is triggered via the PMC, supraspinal input subsides significantly and micturition proceeds in a reflex-like manner. Unsuccessful attempts at micturition result from the inefficient activation of the PAG and PMC during initiation. This condition arises from inadequate antecedent activation of frontoparietal and cingulate cortical regions involved in decision-making and implementation processes related to micturition control. 


\section{Funding}

Open Accessing funding for this article provided by the Swiss National Science Foundation (grant number 32003B_127477/1) and supported by the Swiss Continence Foundation (www. swisscontinencefoundation.ch). Funding to pay the Open Access publication charges for this article was provided by the Swiss Continence Foundation (www.swisscontinencefoundation.ch).

\section{Notes}

This study was awarded the Eugen-Rehfisch-Prize at the 23rd annual meeting of the Forum Urodynamicum 2012 in Zurich, Switzerland. Conflict of Interest: None declared.

\section{References}

Andrew J, Nathan PW. 1964. Lesions on the anterior frontal lobes and disturbances of micturition and defaecation. Brain. 87:233-262.

Barrington F. 1925. The effect of lesions of the hind- and midbrain on micturition in the cat. QJ Exp Physiol Cogn Med. 15:81-102.

Behzadi Y, Restom K, Liau J, Liu TT. 2007. A component based noise correction method (CompCor) for BOLD and perfusion based fMRI. Neuroimage. 37:90-101.

Blok BF. 2002. Central pathways controlling micturition and urinary continence. Urology. 59:13-17.

Blok BF, Holstege G. 1999. The central control of micturition and continence: implications for urology. BJU Int. 83(Suppl 2):1-6.

Blok BF, Holstege G. 1996. The neuronal control of micturition and its relation to the emotional motor system. In: Holstege G, Bandler R, Saper CB, editors. Progress in Brain Research Elsevier Science. p. 113-126.

Blok BF, Sturms LM, Holstege G. 1998. Brain activation during micturition in women. Brain. 121(Pt 11):2033-2042.

Blok BF, Willemsen AT, Holstege G. 1997. A PET study on brain control of micturition in humans. Brain. 120(Pt 1):111-121.

Boujraf S, Summers P, Belahsen F, Prussmann K, Kollias S. 2009. Ultrafast bold fMRI using single-shot spin-echo echo planar imaging. J Med Phys. 34:37-42.

Brett M, Anton JL, Valbregue R, Poline JB. 2002. Region of interest analysis using an SPM toolbox [abstract]. Presented at the 8th International Conference on Functional Mapping of the Human Brain, June 2-6, 2002, Sendai, Japan. Neuroimage. 16:769-1198.

Burgio KL, Locher JL, Goode PS, Hardin JM, McDowell BJ, Dombrowski M, Candib D. 1998. Behavioral vs drug treatment for urge urinary incontinence in older women: a randomized controlled trial. JAMA. 280:1995-2000.

Chou YC, Jiang YH, Harnod T, Kuo HC. 2013. Characteristics of neurogenic voiding dysfunction in cerebellar stroke: a cross-sectional, retrospective video urodynamic study. Cerebellum. 12:601-606.

Corbetta M, Patel G, Shulman GL. 2008. The reorienting system of the human brain: from environment to theory of mind. Neuron. 58:306-324.

Coyne KS, Sexton CC, Kopp ZS, Ebel-Bitoun C, Milsom I, Chapple C. 2011. The impact of overactive bladder on mental health, work productivity and health-related quality of life in the UK and Sweden: results from EpiLUTS. BJU Int. 108:1459-1471.

Coyne KS, Sexton CC, Thompson C, Kopp ZS, Milsom I, Kaplan SA. 2011. The impact of $\mathrm{OAB}$ on sexual health in men and women: results from EpiLUTS. J Sex Med. 8:1603-1615.

Coyne KS, Sexton CC, Thompson CL, Milsom I, Irwin D, Kopp ZS, Chapple CR, Kaplan S, Tubaro A, Aiyer LP et al. 2009. The prevalence of lower urinary tract symptoms (LUTS) in the USA, the UK and Sweden: results from the Epidemiology of LUTS (EpiLUTS) study. BJU Int. 104:352-360.

Craig AD. 2002. How do you feel? Interoception: the sense of the physiological condition of the body. Nat Rev Neurosci. 3:655-666.

Dasgupta R, Critchley HD, Dolan RJ, Fowler CJ. 2005. Changes in brain activity following sacral neuromodulation for urinary retention. J Urol. 174:2268-2272. de Groat WC. 2006. Integrative control of the lower urinary tract: preclinical perspective. Br J Pharmacol. 147(Suppl 2):S25-S40.

de Groat WC. 2002. Plasticity of bladder reflex pathways during postnatal development. Physiol Behav. 77:689-692.

de Groat WC, Wickens C. 2013. Organization of the neural switching circuitry underlying reflex micturition. Acta Physiol (Oxf). 207:66-84.

Dietrichs E, Haines DE. 2002. Possible pathways for cerebellar modulation of autonomic responses: micturition. Scand J Urol Nephrol Suppl. 36:16-20.

Di Gangi Herms AM, Veit R, Reisenauer C, Herms A, Grodd W, Enck P, Stenzl A, Birbaumer N. 2006. Functional imaging of stress urinary incontinence. Neuroimage. 29:267-275.

Eickhoff SB, Jbabdi S, Caspers S, Laird AR, Fox PT, Zilles K, Behrens TE. 2010. Anatomical and functional connectivity of cytoarchitectonic areas within the human parietal operculum. J Neurosci. 30:6409-6421.

Eickhoff SB, Stephan KE, Mohlberg H, Grefkes C, Fink GR, Amunts K, Zilles K. 2005. A new SPM toolbox for combining probabilistic cytoarchitectonic maps and functional imaging data. Neuroimage. 25:1325-1335.

Fowler CJ, Dalton C, Panicker JN. 2010. Review of neurologic diseases for the urologist. Urol Clin North Am. 37:517-526.

Fowler CJ, Griffiths DJ. 2010. A decade of functional brain imaging applied to bladder control. Neurourol Urodyn. 29:49-55.

Fowler CJ, Griffiths D, de Groat WC. 2008. The neural control of micturition. Nat Rev Neurosci. 9:453-466.

Fowler CJ, Panicker JN, Emmanuel A, editors. 2010. Pelvic organ dysfunction in neurological disease. Cambridge, UK: Cambridge University Press.

Fukuyama H, Matsuzaki S, Ouchi Y, Yamauchi H, Nagahama Y, Kimura J, Shibasaki H. 1996. Neural control of micturition in man examined with single photon emission computed tomography using 99mTc-HMPAO. Neuroreport. 7:3009-3012.

Genovese CR, Lazar NA, Nichols T. 2002. Thresholding of statistical maps in functional neuroimaging using the false discovery rate. Neuroimage. 15:870-878.

Heekeren HR, Marrett S, Ungerleider LG. 2008. The neural systems that mediate human perceptual decision making. Nat Rev Neurosci. 9:467-479.

Holstege G. 2005. Micturition and the soul. J Comp Neurol. 493:15-20.

Irwin DE, Kopp ZS, Agatep B, Milsom I, Abrams P. 2011. Worldwide prevalence estimates of lower urinary tract symptoms, overactive bladder, urinary incontinence and bladder outlet obstruction. BJU Int. 108:1132-1138.

Kable JW, Glimcher PW. 2009. The neurobiology of decision: consensus and controversy. Neuron. 63:733-745.

Kavia RB, Dasgupta R, Fowler CJ. 2005. Functional imaging and the central control of the bladder. J Comp Neurol. 493:27-32.

Kuhtz-Buschbeck JP, van der Horst C, Wolff S, Filippow N, Nabavi A, Jansen O, Braun PM. 2007. Activation of the supplementary motor area (SMA) during voluntary pelvic floor muscle contractions-an fMRI study. Neuroimage. 35:449-457.

Loewy AD, Saper CB, Baker RP. 1979. Descending projections from the pontine micturition center. Brain Res. 172:533-538.

Manto M, Oulad Ben Taib N. 2013. The contributions of the cerebellum in sensorimotor control: what are the prevailing opinions which will guide forthcoming studies?. Cerebellum. 12:313-315.

Mehnert U, Boy S, Svensson J, Michels L, Reitz A, Candia V, Kleiser R, Kollias S, Schurch B. 2008. Brain activation in response to bladder filling and simultaneous stimulation of the dorsal clitoral nerve-an fMRI study in healthy women. Neuroimage. 41:682-689.

Murphy K, Birn RM, Handwerker DA, Jones TB, Bandettini PA. 2009. The impact of global signal regression on resting state correlations: are anti-correlated networks introduced? Neuroimage. 44:893-905.

Nishijima S, Sugaya K, Kadekawa K, Ashitomi K, Yamamoto H. 2012. Effect of chemical stimulation of the medial frontal lobe on the micturition reflex in rats. J Urol. 187:1116-1120.

Nour S, Svarer C, Kristensen JK, Paulson OB, Law I. 2000. Cerebral activation during micturition in normal men. Brain. 123(Pt 4):781-789.

Rolls ET, Grabenhorst F. 2008. The orbitofrontal cortex and beyond: from affect to decision-making. Prog Neurobiol. 86:216-244. 
Sakakibara R, Fowler CJ, Hattori T. 1999. Voiding and MRI analysis of the brain. Int Urogynecol J Pelvic Floor Dysfunct. 10:192-199.

Sakakibara R, Hattori T, Yasuda K, Yamanishi T. 1996. Micturitional disturbance after acute hemispheric stroke: analysis of the lesion site by CT and MRI. J Neurol Sci. 137:47-56.

Sakakibara R, Uchida Y, Uchiyama T, Yamanishi T, Hattori T. 2004. Reduced cerebellar vermis activation during urinary storage and micturition in multiple system atrophy: 99mTc-labelled ECD SPECT study. Eur J Neurol. 11:705-708.

Seseke S, Baudewig J, Kallenberg K, Ringert RH, Seseke F, Dechent P. 2006. Voluntary pelvic floor muscle control—an fMRI study. Neuroimage. 31:1399-1407.

Slotnick SD, Moo LR, Segal JB, Hart J Jr. 2003. Distinct prefrontal cortex activity associated with item memory and source memory for visual shapes. Brain Res Cogn Brain Res. 17:75-82.
Tai C, Wang J, Jin T, Wang P, Kim SG, Roppolo JR, de Groat WC. 2009. Brain switch for reflex micturition control detected by FMRI in rats. J Neurophysiol. 102:2719-2730.

Torta DM, Cauda F. 2011. Different functions in the cingulate cortex, a meta-analytic connectivity modeling study. Neuroimage. 56:2157-2172.

Ueki K. 1960. Disturbances of micturition observed in some patients with brain tumour. Neurol Med Chir. 2:25-33.

Yamamoto T, Sakakibara R, Nakazawa K, Uchiyama T, Shimizu E, Hattori T, Kuwabara S. 2010. Neuronal activities of forebrain structures with respect to bladder contraction in cats. Neurosci Lett. 473:42-47.

Zhang H, Reitz A, Kollias S, Summers P, Curt A, Schurch B. 2005. An fMRI study of the role of suprapontine brain structures in the voluntary voiding control induced by pelvic floor contraction. Neuroimage. 24:174-180. 